\title{
Identification and partial characterization of a novel serpin from Eudiplozoon nipponicum (Monogenea, Polyopisthocotylea)
}

Pavel Roudnický ${ }^{1, *}$, Jiří Vorel ${ }^{1}$, Jana Ilgová ${ }^{1}$, Michal Benovics ${ }^{1}$, Adam Norek $^{2}$, Lucie Jedličková ${ }^{3}$, Libor Mikeš ${ }^{3}$, David Potěši $1^{4}$, Zbyněk Zdráhal ${ }^{4,5}$, Jan Dvoř́ák ${ }^{6,7}$, Milan Gelnar ${ }^{1}$, and Martin Kašný1,3

1 Department of Botany and Zoology, Faculty of Science, Masaryk University, Kamenice 753/5, 62500 Brno, Czech Republic

2 Veterinary Research Institute, Hudcova 296/70, 62100 Brno, Czech Republic

3 Department of Parasitology, Faculty of Science, Charles University, Viničná 7, 12844 Prague 2, Czech Republic

4 Central European Institute of Technology, Masaryk University, Kamenice 753/5, 62500 Brno, Czech Republic

5 National Centre for Biomolecular Research, Faculty of Science, Masaryk University, Kamenice 753/5, 62500 Brno, Czech Republic

6 School of Biological Sciences, Medical Biology Centre, Queen's University Belfast, 97 Lisburn Road, Belfast BT9 7BL,

United Kingdom

7 Department of Zoology and Fisheries, Faculty of Agrobiology, Food and Natural Resources, Czech University of Life Sciences in Prague, Kamýcká 129, 16521 Prague, Czech Republic

Received 6 September 2018, Accepted 16 November 2018, Published online 5 December 2018

\begin{abstract}
Background: Serpins are a superfamily of serine peptidase inhibitors that participate in the regulation of many physiological and cell peptidase-mediated processes in all organisms (e.g. in blood clotting, complement activation, fibrinolysis, inflammation, and programmed cell death). It was postulated that in the blood-feeding members of the monogenean family Diplozoidae, serpins could play an important role in the prevention of thrombus formation, activation of complement, inflammation in the host, and/or in the endogenous regulation of protein degradation. Results: In silico analysis showed that the DNA and primary protein structures of serpin from Eudiplozoon nipponicum (EnSerp1) are similar to other members of the serpin superfamily. The inhibitory potential of EnSerp1 on four physiologically-relevant serine peptidases (trypsin, factor Xa, kallikrein, and plasmin) was demonstrated and its presence in the worm's excretory-secretory products (ESPs) was confirmed.

Conclusion: EnSerp1 influences the activity of peptidases that play a role in blood coagulation, fibrinolysis, and complement activation. This inhibitory potential, together with the serpin's presence in ESPs, suggests that it is likely involved in host-parasite interactions and could be one of the molecules involved in the control of feeding and prevention of inflammatory responses.
\end{abstract}

Key words: Eudiplozoon nipponicum, fish parasite, monogenea, Platyhelminths, serpin, inhibitor.

Résumé - Identification et caractérisation partielle d'un nouvelle serpine d'Eudiplozoon nipponicum (Monogenea, Polyopisthocotylea). Contexte : Les serpines sont une super-famille d'inhibiteurs de sérine peptidases qui participent, dans tous les organismes, à la régulation de nombreux processus physiologiques et à médiation par les peptidases cellulaires (par exemple la coagulation sanguine, l'activation du complément, la fibrinolyse, l'inflammation et la mort cellulaire programmée). Il a été postulé que chez les Monogènes de la famille Diplozoidae, qui sont hématophages, les serpines pourraient jouer un rôle important dans la prévention de la formation de thrombus, l'activation du complément, l'inflammation chez l'hôte et/ou la régulation endogène de la dégradation des protéines. Résultats : Une analyse in silico a montré que l'ADN et les structures primaires protéiques de la serpine d'Eudiplozoon nipponicum (EnSerp1) sont similaires aux autres membres de la superfamille des serpines. Le potentiel inhibiteur d'EnSerp1 sur quatre sérine peptidases physiologiquement pertinentes (la trypsine, le facteur Xa, la kallikréine et la plasmine) a été démontré et sa présence dans les produits excréteurs de sécrétion du ver (ESP) a été confirmée. Conclusion: EnSerp1 influence l'activité des peptidases qui jouent un rôle dans la coagulation sanguine, la fibrinolyse et l'activation du complément. Ce potentiel inhibiteur, ainsi que la présence de la serpine dans les ESP, suggèrent qu'elle est probablement impliquée dans les interactions hôte-parasite et pourrait être l'une des molécules impliquées dans le contrôle de l'alimentation et la prévention des réponses inflammatoires.

*Corresponding author: p.roudnicky@mail.muni.cz

This is an Open Access article distributed under the terms of the Creative Commons Attribution License (http://creativecommons.org/licenses/by/4.0), which permits unrestricted use, distribution, and reproduction in any medium, provided the original work is properly cited. 


\section{Introduction}

Almost $40 \%$ of peptidases deposited in the MEROPS database (Release 12.0) are serine peptidases (SPs) and up to $70 \%$ of all deposited inhibitors are SP inhibitors, $25 \%$ of which are serpins (Serine Peptidase Inhibitors) [13, 21, 84]. Although nucleotide/amino acid sequences of serpins are not highly conserved across organisms (AA similarity around 30\% [13]), their secondary structures typically consist of three $\beta$-sheets (A, B, C) and eight to nine $\alpha$-helices $[21,29]$. Serpins are usually 350-450 AAs long, which corresponds to $40-60 \mathrm{kDa}$ $[20,61,88]$. Importantly, a characteristic sequence motif, a reactive centre loop (RCL) containing a scissile bond between $\mathrm{P} 1$ and P1' residues, is responsible for the serpins' inhibitory effect towards peptidases. This structure is bound and cleaved by the active site of target SP, which results in a distortion and inactivation of the enzyme [21,65].

In addition to having an inhibitory effect on SPs [14, 21, 32, $34,61]$, some serpins are also capable of inhibiting peptidases of other catalytic types, such as cysteine peptidases: a human SCCA1 serpin interacts with cathepsins K, L, and S [87], while cowpox virus CrmA serpin inhibits interleukin- $\beta$ converting enzyme, which is a caspase [51]. Some serpins lack inhibitory properties and have other biological roles. They function for instance as hormone transporters, which is the case of the human corticosteroid-binding globulin [24], as chaperones, in particular chaperone HSP47 (from bacteria to mammals) [39], or as putative storage proteins, which is the case of chicken ovalbumin [21].

Among parasitic flatworms, there are many reports of both SPs and serpin inhibitors. These enzymes have various functions including immune evasion, collagenolytic activity, and digestion of the host's tissue, which is related to host invasion and migration through the body $[2,12,16,17,52$, $70,78,79]$. It has also been reported that serpins probably play a key role in immune evasion or immunomodulation in, e.g., Echinococcus multilocularis [64], Schistosoma mansoni [22], and Schistosoma japonicum [98]; another serpin from Schistosoma haematobium inhibits blood coagulation during feeding [9], in Schistosoma mansoni another one may acts as a regulator of cercarial elastase activity [60], while a serpin from Clonorchis sinensis participates in the development of the specific life stages of the parasite [43].

Within the Monogenea, data about SPs and their inhibitors are scarce. So far, only a single report exists on potential SP activity in whole worm extracts from Neobenedenia girellae [28]; the authors hypothesise that SPs could play an important role in the life cycle of the parasite, influencing processes such as egg laying by adults and the swimming of oncomiracidia. Our experimental organism, a diplozoid sanguinivorous monogenean Eudiplozoon nipponicum Goto, 1891 (Polyopisthocotylea) is a common ectoparasite that inhabits the gills of cyprinid fish, most frequently the common carp (Cyprinus carpio). In monogeneans, blood digestion takes place only partly in the gut lumen [40] and for the most part, digestion occurs in specialised hematin cells of the gastrodermis (intestinal epithelium) [53]. Little is known about the molecules secreted by monogeneans during blood uptake. This contrasts with knowledge on some haematophagous ectoparasites belonging to other taxa, such as ticks, which produce two functionally predominant groups of molecules in their salivary glands - antihemostatic and immunomodulatory factors. In these organisms, serpins have been identified as effective regulators of host inflammatory processes, complement activation, blood clotting, and platelet aggregation [15, 57, 80, 81]. The present work is part of our on-going research to identify and understand the key peptidases and their inhibitors produced by E. nipponicum [37, 40, 41]. In the present study, we report the first evidence of a serpin molecule produced by Monogenea and present a description of its basic molecular and functional characteristics.

\section{Methods}

\section{Parasite material}

Adults of E. nipponicum were collected from freshly sacrificed specimens of Cyprinus carpio caught in the Mušov lowland reservoir, Czech Republic $\left(48^{\circ} 53^{\prime} 12^{\prime \prime} \mathrm{N}, 16^{\circ} 34^{\prime} 37^{\prime \prime} \mathrm{E}\right)$. Isolation of the individual worms from the gills was performed under a TH4-200 stereomicroscope (Olympus). Living worms were taxonomically identified under a BX50 light microscope (Olympus) equipped with a differential interference contrast (Nomarski DIC), and species identity was confirmed by sequencing [62].

For the preparation of excretory-secretory products (ESPs), worms (app. 100 individuals) were gently washed in $10 \mathrm{mM}$ PBS pH 7.2 and incubated in fresh buffer of the same composition for $3 \mathrm{~h}$ at room temperature (RT). Samples were concentrated on Amicon ${ }^{\circledR}$ Ultra $3 \mathrm{~K}$ centrifugal filters (Merck Millipore). Crude worm extract (CWE) was prepared by gently washing E. nipponicum adults (five individuals) in $10 \mathrm{mM}$ PBS $\mathrm{pH} 7.2$ and manually homogenised in $0.1 \mathrm{M}$ acetate buffer $\mathrm{pH}$ 5, sonicated with BioLogics 150 VT ultrasonic homogeniser (60\% amplitude, three cycles of $30 \mathrm{~s})$, centrifuged (16 $000 \times \mathrm{g}$, $20 \mathrm{~min}, 4{ }^{\circ} \mathrm{C}$ ), and the supernatant was collected.

Protein concentration in ESP and CWE was determined using a Quaint-i ${ }^{\mathrm{TM}}$ Protein Assay Kit (Life Technologies) and SpectraMax i3 fluorometer (Molecular Devices). Prior to their use, samples were stored at $-80^{\circ} \mathrm{C}$.

\section{In silico sequence analyses}

A nucleotide sequence with a complete open reading frame (ORF) encoding EnSerp1 was obtained from assembled transcripts from E. nipponicum transcriptome (the E. nipponicum Transcriptome Shotgun Assembly project has been deposited at DDBJ/EMBL/GenBank under Accession Number GFYM00000000) [7]. Additionally, two other serpin-coding sequences were identified; EnSerp1 (E_nip_trans_58759_m. 371742) was selected for this study due to the higher number of transcript copies (983 150.64 transcripts per million), whereas the number of copies of other serpin genes was one (E_nip_trans_50452_m.341543) and two (E_nip_trans_ 65948_m.402754) orders lower. Deduced protein sequence was analysed using the basic local alignment search tool (BLAST), available at the National Center for Biotechnology Information website (http://ncbi.nlm.nih.gov). From all serpins 
used for the phylogenetic analysis (see below), four sequences with the highest level of similarity to EnSerp1 were chosen to analyse the conserved areas in the alignment using Geneious 7.1.9 software (Biomatters Ltd.). Other analyses of serpin sequences were performed with Proteomics and sequence analysis tools (http://ca.expasy.org/tools). Secondary and tertiary structure predictions were carried out via web portal Phyre2, set to intensive mode [47]. Subsequent graphic visualisation and analysis of the EnSerp1 molecule were performed with the UCSF Chimera software tool, version 1.10.2 [77] in combination with Modeller 9.16 [86].

\section{Phylogenetic analysis}

For the phylogenetic analysis, amino acid sequences of serpin homologs from 13 platyhelminth taxa were aligned with EnSerp1 using ClustalW software [92]. The list of sequences obtained from GenBank, including the EnSerp1 sequence, is presented in Supplementary file 1. The predicted AA sequence of a serpin from Gyrodactylus salaris (scf7180006950201) was obtained from genome data deposited in the WormBase ParaSite database [30, 31] (accession no. PRJNA244375). Sequence alignment was checked and optimised manually to avoid ambiguously aligned regions. ModelGenerator v. 0.851 [46] was employed to test 12 evolutionary models and to approximate the most suitable one using the Bayesian information criterion (BIC). Phylogenetic trees were inferred according to Bayesian inference (BI) and Maximum likelihood (ML) in the MrBayes 3.2 [85] and RaxML v 8.1.X programmes, respectively [89]. Bayesian inference was carried out using the Metropolis-coupled Markov chain Monte Carlo $\left(\mathrm{MC}^{3}\right)$ algorithm with two parallel runs, using one cold and three hot chains. The computation ran for $10^{6}$ generations and sampling tree topologies were constructed every $10^{2}$ generations. Thirty percent of all saved trees were discarded as a relative burn-in period based on a standard deviation split frequency value $(<0.01)$. Posterior probabilities were calculated as the frequency of samples recovering any particular clade. Clade support for ML was assessed by 1000 bootstrap pseudoreplicates, subtree pruning and regrafting (SPR), and nearest neighbour interchange (NNI) branch swapping algorithms were applied.

\section{RNA, cDNA, and plasmid preparation}

E. nipponicum RNA was isolated using a High Pure RNA Tissue Kit (Roche). A Transcriptor First Strand cDNA Synthesis Kit (Roche) with anchored-oligo(dT) $)_{18}$ primer was used for reverse transcription of RNA to cDNA.

PCR was performed as described previously [41], using specific primers for the E. nipponicum EnSerp1 gene (EnSerp1 forward: 5'-ATGTGCGCTTGTCCTAATAG-3', EnSerp1 reverse: $5^{\prime}$-TTATTTGGAAGGTTCTGGATCC- $3^{\prime}$ ) and higher annealing temperature $\left(55^{\circ} \mathrm{C}\right)$. The PCR products $(1200 \mathrm{bp})$ were resolved in $1 \%$ agarose gel, purified by a MinElute PCR Purification Kit (Qiagen) and sub-cloned into a pJET1.2 cloning vector (CloneJET PCR Cloning Kit, Thermo Scientific), which was used to transform E. coli XL-1 Blue (Novagen). pJET1.2 constructs were isolated using a High Pure Plasmid Isolation Kit (Roche) and sequenced with pJET1.2 forward and reverse primers from the kit (DNA Sequencing Laboratory, Faculty of Science, Charles University, Prague).

Expression vector $\mathrm{pET}-22 \mathrm{~b}(+)$ containing the EnSerp1 insert (1200 bp) was synthesised by GeneScript company, with the coding sequence for His-tag on C-terminus. E. coli TOP10 cells were transformed by this construct for DNA plasmid propagation (heat shock $42{ }^{\circ} \mathrm{C}$ for $45 \mathrm{~s}$ ). Plasmids were isolated using a High Pure Plasmid Isolation Kit (Roche) and used to transform ArcticExpress (DE3) Competent Cells (Agilent Technologies), according to the manufacturer's instructions. Positive colonies were verified by sequencing and sequences analysed by Geneious 7.1.9.

\section{Expression of recombinant E. nipponicum serpin (rEnSerp1) and its purification}

Overnight culture $(5 \mathrm{~mL}, \mathrm{OD} \approx 2)$ was inoculated into $500 \mathrm{~mL}$ of a fresh LB medium (L3022, Sigma-Aldrich) with ampicillin $(100 \mu \mathrm{g} / \mathrm{mL})$. Bacteria were grown at a temperature of $30{ }^{\circ} \mathrm{C}$ at $200 \mathrm{rpm}$ until $\mathrm{OD}=0.8$ was reached, then cooled down to $12{ }^{\circ} \mathrm{C}$ and induced by IPTG $(0.5 \mathrm{mM})$ for $18 \mathrm{~h}$. Harvested cells were lysed in a binding buffer (specifications below) by sonication on ice, and subsequently centrifuged at $10000 \times g$ for $40 \mathrm{~min}$ at $4{ }^{\circ} \mathrm{C}$. Soluble rEnSerp 1 was purified from the supernatant by immobilised metal affinity chromatography (IMAC) using $\mathrm{Ni}^{2+}$ HisTrap columns $(1 \mathrm{~mL}$, GE Healthcare) connected to FPLC (ÄKTA, GE Healthcare).

Buffers used in the individual stages of purification were composed as follows: binding buffer $-50 \mathrm{mM}$ Tris- $\mathrm{HCl} \mathrm{pH} 8$, $10 \mathrm{mM}$ imidazole, $300 \mathrm{mM} \mathrm{NaCl}, 5 \%$ glycerol, $0.05 \%$ Tween; elution buffer - $50 \mathrm{mM}$ Tris- $\mathrm{HCl} \mathrm{pH} 8,500 \mathrm{mM}$ imidazole, $300 \mathrm{mM} \mathrm{NaCl}, 5 \%$ glycerol, $0.05 \%$ Tween. Protein purity was evaluated in a $4-15 \%$ TGX SDS-PAGE gel under reducing conditions (Bio-Rad Mini-Protean). In a sample buffer, wells contained $5 \mu \mathrm{g}$ of protein. Gel documentation was performed in a calibrated densitometer GS-900 ${ }^{\mathrm{TM}}$ (Bio-Rad). Recombinant EnSerp1 was deprived of imidazole and salts using PD-10 columns (GE Healthcare), and then transferred into a $100 \mathrm{mM}$ HEPES buffer (pH 7.5 with $300 \mathrm{mM} \mathrm{NaCl}, 10 \mathrm{mM} \mathrm{CaCl}_{2}$, and $0.05 \%$ Brij L23), i.e. the same buffer that was used for inhibition assays. Protein concentration was determined using a Quaint-iT ${ }^{\mathrm{TM}}$ Protein Assay Kit (Life Technologies) and a SpectraMax i3 fluorometer (Molecular Devices).

\section{LC-MS analyses}

A major band of a size corresponding to rEnSerp1 (around $45 \mathrm{kDa}$ ) was manually excised from the $1 \mathrm{D}$ gel, destained, and incubated with trypsin (Promega) at $37{ }^{\circ} \mathrm{C}$ for $2 \mathrm{~h}$. Peptides were extracted from the gel using a solution of $50 \%$ acetonitrile with $5 \%$ formic acid prior to LC-MS/MS analysis.

$\mathrm{E} / \mathrm{S}$ products of E. nipponicum were also analysed using LC-MS/MS. A sample of ESP was processed using a filter-assisted sample preparation technique (FASP; using Ultracel-10 kDa Membrane units), and the resulting peptide mixture was analysed using the LC-MS/MS system.

LC-MS/MS analyses of all peptide mixtures were carried out on an RSLCnano liquid chromatograph connected online to an Orbitrap-Elite mass spectrometer (Thermo Scientific). 
In-gel or E/S product digests were analysed using a 40 or $100 \mathrm{~min}$ long nonlinear gradient, respectively (mobile phase A: $0.1 \%$ formic acid in water; mobile phase B: $0.1 \%$ formic acid in $80 \%$ acetonitrile). MS and MS/MS (HCD fragmentation) spectra were recorded in an Orbitrap analyser (resolution 60000 at $400 \mathrm{~m} / \mathrm{z}$ and 15000 at $400 \mathrm{~m} / \mathrm{z}$, respectively).

MS/MS data were processed using Proteome Discoverer software, version 1.4, and database searches executed using the Mascot search engine (version 2.6, Matrix Science). $\mathrm{MS} / \mathrm{MS}$ data for in-gel digest were searched against a cRAP contaminant database (based on http://www.thegpm.org/crap/), local database containing a serpin sequence and UniRef100 database (all taxonomies, no restrictions, ftp://ftp.ebi.ac.uk/ pub/databases/uniprot/uniref/uniref100/uniref100.fasta.gz; version 2017-06, 112447146 sequences in total). The cRAP database and concatenated database of E. nipponicum transcripts, C. carpio proteins (downloaded from NCBI), and the UniRef100 protein database for platyhelminths (downloaded from UniProt.org) were used to acquire $\mathrm{E} / \mathrm{S}$ sample data. Modifications for all database searches were set as follows: oxidation (M), deamidation $(\mathrm{N}, \mathrm{Q})$, and acetylation (Protein $\mathrm{N}$-term) as optional modifications, with carbamidomethylation (C) as a fixed modification. Enzyme specificity was tryptic or semitryptic for in-gel digest and E/S sample data, respectively, with one allowed miscleavage. Only peptides with a Mascot Ion Score above 40, rank 1, and at least six amino acids long were considered during the confirmation of presence of rEnSerp1 and/or EnSerp1 proteins.

\section{Production of antibodies}

Anti-rEnSerp1 antibodies were produced in two ICR/CD1 mice (ENVIGO) injected intraperitoneally with $50 \mu \mathrm{g}$ of rEnSerp1 cut as a band from a polyacrylamide gel after SDS-PAGE. The strip of gel containing the antigen was washed and homogenised, as described previously [40]. The mice were boosted twice at 14-day intervals by intramuscular injections of purified antigen $(15 \mu \mathrm{g})$ in sterile saline. Blood was collected from the animals under a deep ketamine/xylazine anaesthesia 14 days after the last injection, and sera were obtained by centrifugation. Control (pre-immune) sera were collected from the same mice prior to immunisation.

\section{Western blot analysis}

The presence of EnSerp1 in ESP and CWE, and specificity of anti-rEnSerp1 antibodies were tested on Western blots. ESP, CWE, and rEnSerp1 samples were run on SDS-PAGE under the conditions described above. Proteins were transferred onto a PVDF membrane (Bio-Rad) using Trans-Blot Turbo ${ }^{\mathrm{TM}}$ (Bio-Rad) with the protocol set to a constant $1.3 \mathrm{~A}$ for $10 \mathrm{~min}$. After overnight blocking in $10 \mathrm{mM}$ PBS, pH 7.2, containing 5\% non-fat milk, $2.5 \%$ BSA, and $0.05 \%$ Tween 20 , the membranes were incubated with mouse anti-rEnSerp1 antisera (1:50) in a blocking buffer for $1.5 \mathrm{~h}$. Mouse pre-immune sera were used as a negative control. After washing in PBS $(3 \times 5 \mathrm{~min})$, the membranes were incubated with peroxidase-conjugated goat anti-mouse IgG (1:400, AP124P, Sigma-Aldrich) in the blocking buffer for $1 \mathrm{~h}$. After the final washing $(3 \times 5 \mathrm{~min})$, reactions were visualised using an Opti-4CN ${ }^{\mathrm{TM}}$ substrate kit (Bio-Rad), according to the manufacturer's instructions. Signal intensity was read in a calibrated densitometer GS-900 ${ }^{\mathrm{TM}}$ (Bio-Rad).

\section{Peptidase inhibition assays}

The inhibitory effect of rEnSerp1 was tested with commercially available peptidases (Sigma-Aldrich) in the presence of the respective fluorogenic peptide substrates in black, flat-bottom microtiter plates (Nunc): human thrombin (T6884) + VPR-AMC (B9385, Sigma-Aldrich), bovine factor X activated (F9302) + IEGR-AMC (B9936, Sigma-Aldrich), human plasmin (10602361001) + ALK-AMC (A8171, SigmaAldrich), human plasma kallikrein (K2638) + FR-AMC (I-1160.0050, Bachem), porcine elastase (E7885) + AAPVAMC (S4760, Sigma-Aldrich), and porcine trypsin (T6567) + GPR-AMC (I-1150.0025, Bachem). Mixtures of the buffer (300 mM NaCl, $10 \mathrm{mM} \mathrm{CaCl}_{2}, 0.05 \%$ Brij L23, pH 7.5) and substrate served as blanks. Substrate and enzyme concentrations were $20 \mathrm{nM}$ and $10 \mathrm{nM}$, respectively. Each peptidase was preincubated with $0.425 \mu \mathrm{M}$ EnSerp 1 for $10 \mathrm{~min}$ at RT before adding a corresponding substrate. The relative fluorescence of released aminomethyl coumarin was measured in kinetic cycles at $30 \mathrm{~s}$ intervals for $45 \mathrm{~min}$ in the SpectraMax i3 fluorometer (Molecular Devices) at excitation and emission wavelengths 355 and $460 \mathrm{~nm}$, respectively. Measurements were carried out in triplicate and the experiment was repeated twice. These data were normalised between zero and $100 \%$ of the peptidase activity. Resulting graphs represent an arithmetic average of all measurements. Standard deviation is expressed as an error bar.

Trypsin and factor Xa were also assayed in reaction with a bacterial extract without the presence of rEnSerp1 to eliminate the possibility of a false result due to possible bacterial contaminants. The sample of a bacterial extract (ArcticExpress $E$. coli without an inserted gene coding the rEnSerp1) was prepared in the same way as the rEnSerp1, i.e. by adopting IMAC and FPLC during the sample preparation.

\section{Results}

\section{In silico analysis of EnSerp1 sequence}

The complete ORF of the EnSerp1 gene submitted to the database (GenBank: MF288891.1) was determined to be a $1200 \mathrm{bp}$ long sequence encoding 399 amino acids. The predicted molecular weight of the protein was $44.65 \mathrm{kDa}$ (45.64 with His-tag) and the calculated pI was 5.59. No signal peptide was found. A conserved motif typical of serpins was identified through alignment with four of the most closely similar serpin sequences from other platyhelminths: Echinococcus multilocularis (GenBank: CDS35969.1), Schistosoma haematobium (GenBank: XP_012797533.1), Echinococcus granulosus (GenBank: CDS22753.1), and Taenia solium (GenBank: ATG83400.1]). The most relevant parts of the sequence are highlighted in Figure 1A. Two additional serpin 
A

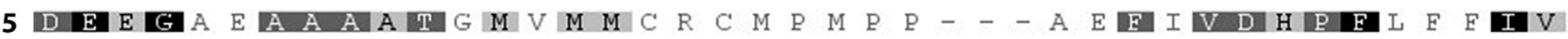

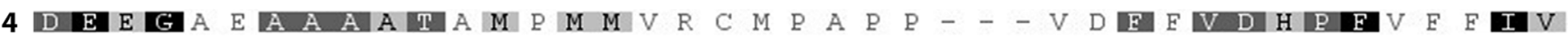

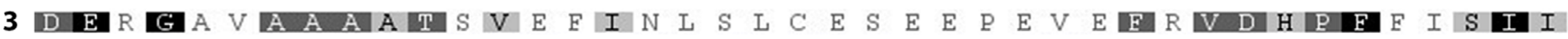

2 DE E G A E A A A A T A M P M M V R C M P A P P - - V D F E V D H P E I E E I V

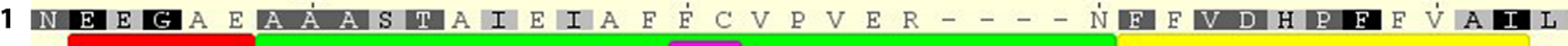

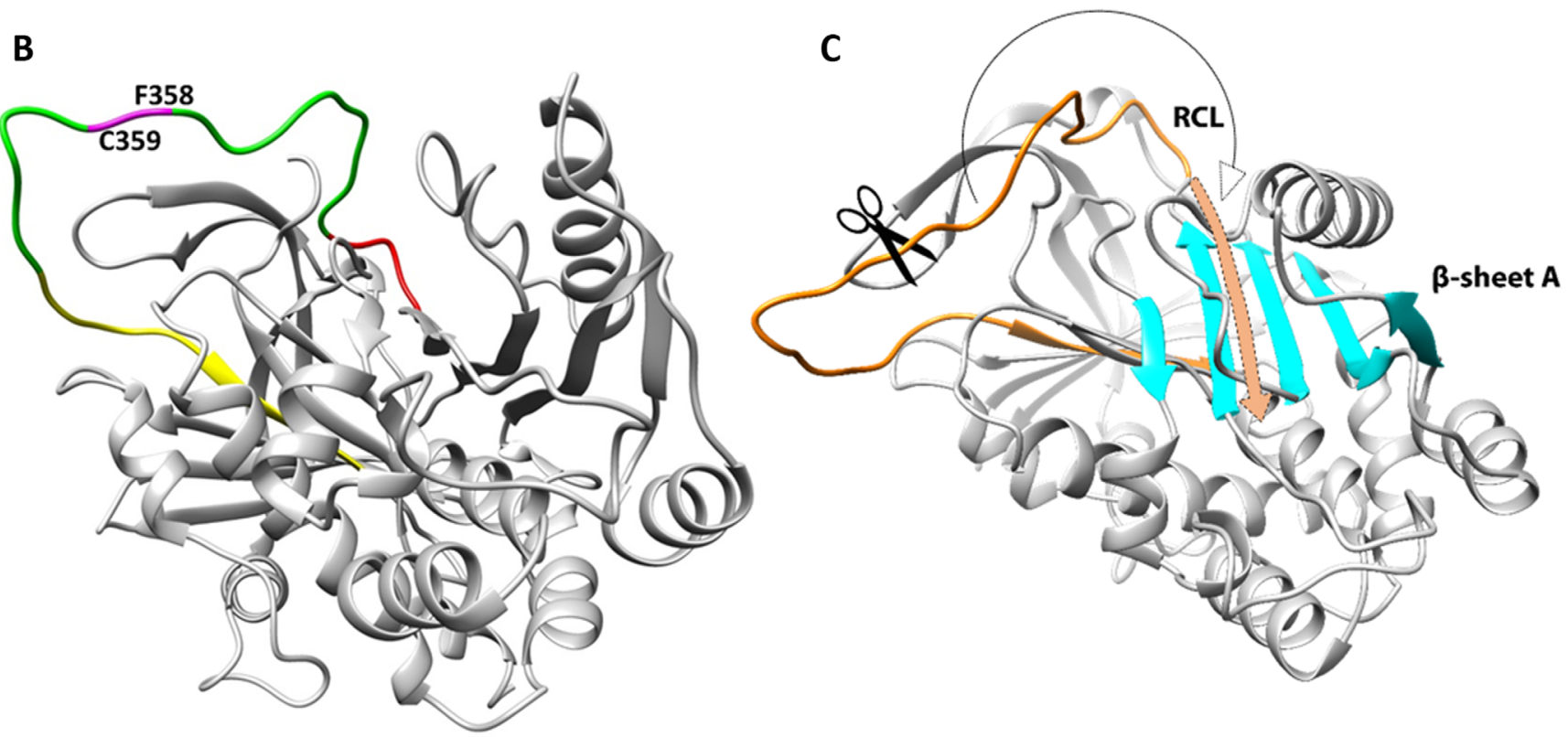

Figure 1. (A) Alignment of the EnSerp1 sequence with four of the most similar serpin sequences of other platyhelminths: 1, EnSerp1 from Eudiplozoon nipponicum (GenBank: MF288891.1); 2, Echinococcus multilocularis (GenBank: CDS35969.1); 3, Schistosoma haematobium (GenBank: XP_012797533.1); 4, Echinococcus granulosus (GenBank: CDS22753.1); 5, Taenia solium (GenBank: ATG83400.1). Conserved motifs characteristic for serpins are highlighted. The serpin motif $\left(\mathrm{E}^{342}-\mathrm{E}^{346}\right)$ shown in red is part of the reactive centre loop (RCL, $\mathrm{A}^{347}-$ $\mathrm{N}^{365}$ ), shown in green. Immediately after RCL, follows serpin signature $\left(\mathrm{F}^{366}-\mathrm{I}^{376}\right)$ in yellow. Scissile bond is situated within the RCL between P1 $\left(\mathrm{F}^{358}\right)$ and P1' $\left(\mathrm{C}^{359}\right)$ residue, shown in magenta. (B) Predicted 3D structure of EnSerp1. Coloured areas of the molecule correspond to the sequence highlighted in Figure 1A. (C) RCL and $\beta$-sheet A. After the peptidase cleaves the scissile bond within RCL (in orange), the residual part of RCL is incorporated as a new strand into $\beta$-sheet A (in cyan).

sequences identified in E. nipponicum transcriptome (E_nip_trans_50452_m.341543 and E_nip_trans_65948_m. 402754) shared $97.3 \%$ and $94.5 \%$ similarity with EnSerp1, respectively.

Six templates for predicting EnSerp1's 3D structure based on heuristics to maximise confidence, percentage identity, and amino acid alignment coverage were selected using the Phyre2 web tool [47] (Fig. 1B). For templates, we used the following molecules: in two cases antithrombin III (PDB: $1 \mathrm{ATT}$ and 2B5T) [42, 67], in another two cases plasminogen activator inhibitor-1 (PAI-1) (PDB: 1LJ5 [unpublished Stein PE and Baek K, 2002] and 4DTE [3]), in one case heparin cofactor II (PDB: 1JMO) [4], and likewise in one case the molecule known as chaperone Hsp47/Serpinh1 (PDB: 3ZHA) [95]. According to these templates, the most probable 3D structure for EnSerp1 was built with an over $90 \%$ confidence for $95 \%$ of residues. The theoretical tertiary structure is composed of nine right-hand-coiled $\alpha$-helices and three antiparallel $\beta$-sheets.

\section{Phylogenetic analysis}

The resulting 429-residue-long amino acid alignment built from 30 sequences contained 25 invariable sites. An $\mathrm{LG}+\mathrm{I}+\mathrm{G}$ [56] model was calculated by ModelGenerator as the optimal evolutionary model and applied in Bayesian inference and Maximum likelihood analyses. Both methods yielded trees with identical topologies. The resulting BI tree with posterior probabilities (PP) obtained by BI analysis and Maximum likelihood bootstrap values (BS) along the branches is presented in Figure 2.

The resulting cladogram divided platyhelminth serpin homologs in two well-supported groups (subfamilies) ( $\mathrm{PP}=1$, BS = 100), A and B (see Fig. 2). EnSerp1 clustered with platyhelminth serpin homologs in Group A. Its position as a sister clade to serpins of the Trematoda class within the clade is weakly supported by BI and not supported by ML analyses. Serpin homologs of trematodes form a well-supported monophyletic clade within both subfamilies. Within Group A, 


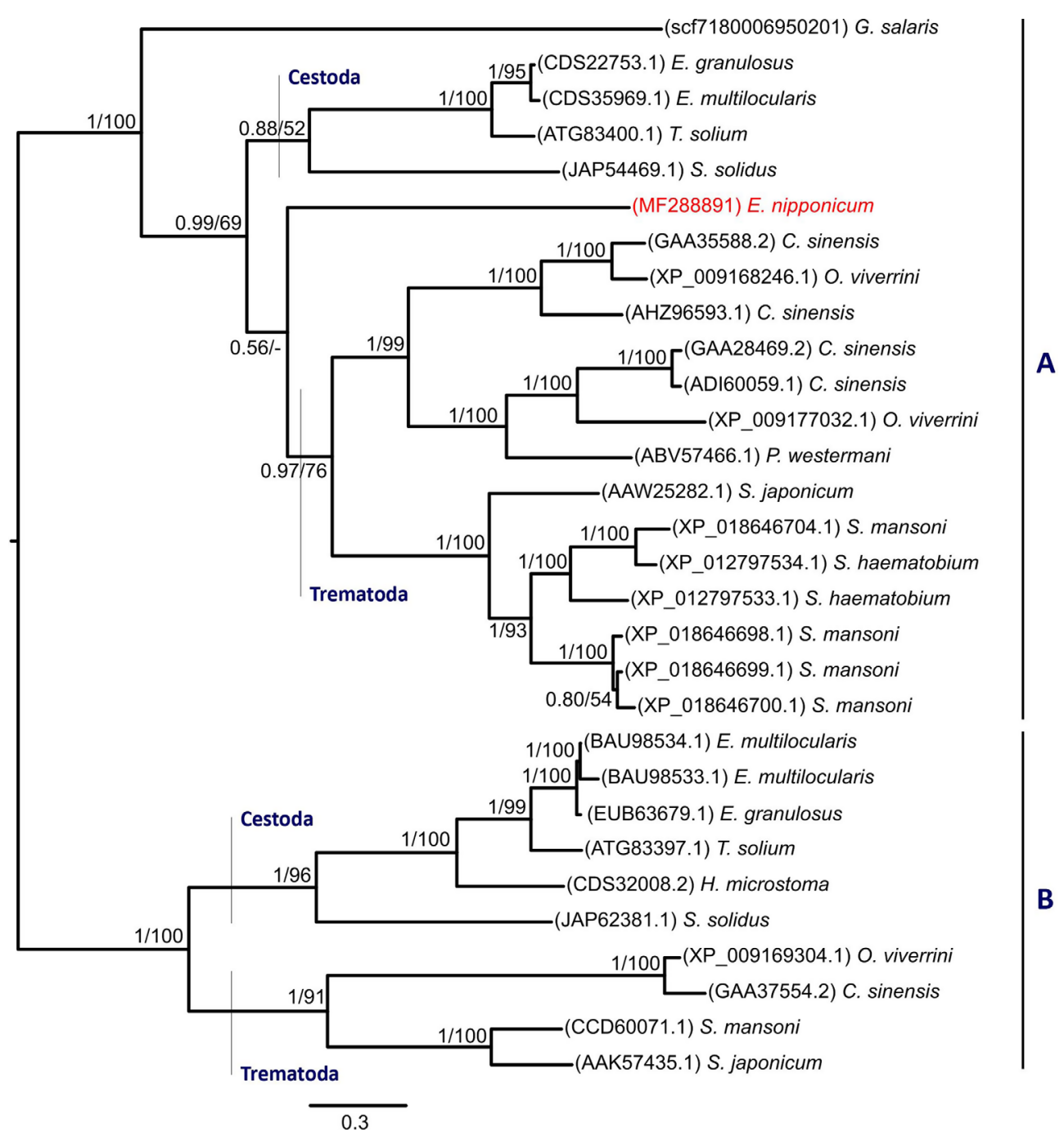

Figure 2. A phylogram of platyhelminth serpin homologs, Bayesian inference analysis. Values along the branches indicate posterior probabilities and bootstrap values resulting from Bayesian inference and Maximum likelihood analyses, respectively. Proportional lengths of the branches correspond to the expected number of amino acid substitutions per site. The resulting tree is mid-point rooted in order to visualise the clustering of representative subfamilies. Newly obtained Eudiplozoon nipponicum serpin homolog (EnSerp1) is labelled red.

serpin orthologs of cestodes form a well-supported clade, with the exception of a serpin ortholog from Schistocephalus solidus, whose position is supported only moderately or weakly $(\mathrm{PP}=0.88, \mathrm{BS}=52)$. Cestode serpin homologs of Group B, on the other hand, in both analyses form a well-supported clade that includes all representatives.

\section{The expression of recombinant serpin and MS analysis}

A $45 \mathrm{kDa}$ band corresponding to the theoretical size of rEnSerp1 appeared in the gel after electrophoresis (Fig. 3). Mass spectrometry data analysis had shown that EnSerp1 is the best-scoring protein in the given band (27 peptides and sequence coverage $75 \%$ ). A search against the UniRef100 database did not indicate the presence of any other major protein component in this band. An MS examination of other bands from the gel showed that two minor bands represented fragments of rEnSerp1, while the remaining bands were bacterial contaminants.

E/S products were also subjected to an LC-MS analysis to verify the presence of EnSerp1. It was identified in this sample by 20 peptides that covered $63 \%$ of the amino acid sequence (data not shown). The identity of $45 \mathrm{kDa}$ rEnSerp1 on blots was confirmed with mouse anti-rEnSerp1 antibodies and commercial mouse anti-His-tag antibodies (Invitrogen, cat. no. 372900). Anti-rEnSerp1 antibodies also reacted with the band of a corresponding size in ESP, but not in CWE (Fig. 3).

\section{Peptidase inhibition assays}

The inhibitory effect of rEnSerp1 on four peptidases (trypsin, factor Xa, plasmin, and plasma kallikrein) was determined by a kinetic measurement of residual peptidase activities in the presence of the appropriate fluorogenic substrates. 


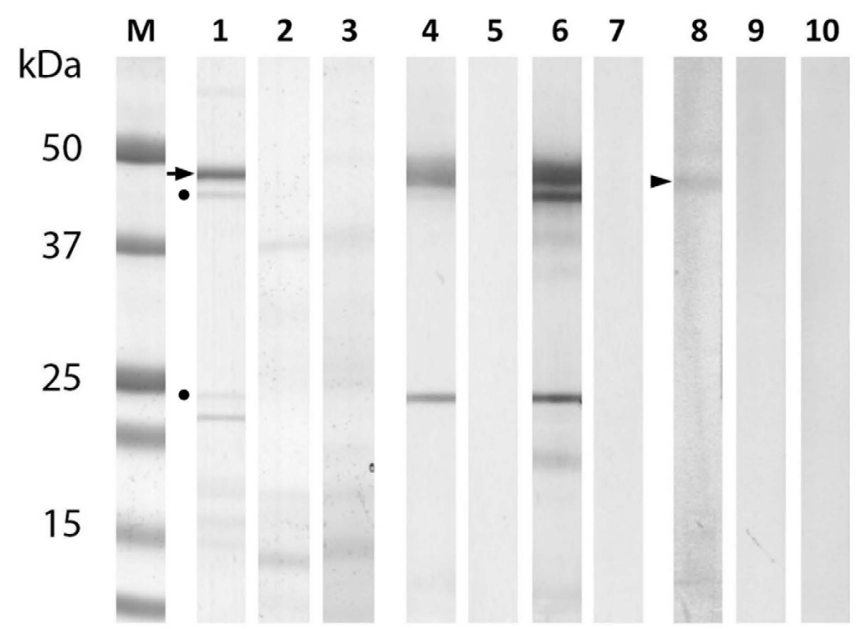

Figure 3. SDS PAGE and Western blots with rEnSerp1, ESP and CWE. Lines 1-3, 1D gel. Lines 4-10, Western blot. M, protein standard; 1, rEnSerp1; 2, ESP; 3, CWE sample; 4, rEnSerp1 with anti-HIS antibodies; 5, rEnSerp1 without primary antibodies; 6, rEnSerp1 with anti-rEnSerp1 sera; 7, rEnSerp1 with pre-immune sera; 8, ESP with anti-rEnSerp1 sera; 9, ESP with pre-immune sera; 10, CWE with anti-rEnSerp1 sera. Arrow points to the expected recombinant EnSerp1 band. Arrowhead points to the natural form of EnSerp1 in the ESP sample. Dots indicate fragmented parts of rEnSerp1.

rEnSerp1 inhibited trypsin activity by $8.5 \pm 3.8 \%$, factor Xa by $40.2 \pm 2.5 \%$, plasmin by $27.1 \pm 7.7 \%$, and plasma kallikrein by $17 \pm 19.2 \%$ (Figs. 4A-4D). It had no effect on thrombin and pancreatic elastase (not shown). Measurement with an rEnSerp1-free bacterial lysate showed either no inhibition or even enhancement of substrate cleavage due to possible residual activity of a low amount of bacterial peptidases (Figs. 4E and 4F).

\section{Discussion}

The Eudiplozoon nipponicum (family Diplozoidae), a haematophagous ectoparasite of the common carp, belongs to the highly radiated class of Monogenea. So far, this invasive parasite species was investigated mainly in studies focused on taxonomy, phylogeny, zoogeography, morphology/anatomy, basic biology, ecology, ecotoxicology, and pathogenicity $[54,93,100]$. The E. nipponicum can have a pathogenic effect on fish. In particular, blood intake by worms attached to the gills can eventually lead to hypochromic microcytic anaemia [45], while the small ruptures of gill lamellae can become a gateway for secondary bacterial and viral infections [5, 71, 97]. While participation of parasite molecules in pathological processes has been described for other helminths [27, 44], our knowledge of the particulars of parasite-host interactions at a molecular level and the functional contexts for particular monogenean molecules is lagging far behind. The only study so far that focused on monogenean SPs is a general study by Hirazawa et al. [28], while other studies investigated the primary structure of cathepsin L of the mucophagous Neobenedenia melleni [82] and proposed functional characterisation of cysteine and aspartic peptidases of $E$. nipponicum, which seem to play a role in blood digestion and vitellogenesis [41]. Two other studies related to E. nipponicum molecules were published recently; the first dealt with stefin, an inhibitor of cysteine peptidases, which can inhibit the activity of cathepsins L3 and B, thus possibly regulating their functions in the digestive process and reproduction, respectively [37]. The second study focused on a broad range of cysteine peptidases, their annotation and functional characterisation, while also proposing extracellular digestion in blood-feeding monogeneans [40].

The present study is the first characterisation of monogenean serpin, an inhibitor of SPs. In a transcriptome of adult E. nipponicum, we identified three highly similar serpin-coding sequences, possibly paralogs resulting from gene duplications. The most abundant one, EnSerp1, was selected for heterologous expression in E. coli. The recombinant form of E. nipponicum serpin (rEnSerp1) possesses 399 amino acids (without His-tag). This corresponds to the usual size of serpins in other organisms (350-400 AA) [20, 61, 88]. The molecular structure of the EnSerp1 protein molecule includes conserved regions that are specific to the serpin family: a serpin motif $\left(\mathrm{E}^{342}-\mathrm{E}^{346}\right)$, serpin signature $\left(\mathrm{F}^{366}-\mathrm{I}^{376}\right)$, and a hypervariable reactive centre loop (RCL) located in-between them (see also Figs. 1A and 1B). Alongside the serpin motif, EnSerp1 also contains a three-alanine region $\left(\mathrm{A}^{347}-\mathrm{A}^{349}\right)$ assumed to be of crucial importance in serpins with inhibitory function because it has the ability to change conformation after cleavage of the scissile bond [38]. Differences in this region are usually linked to other general properties of serpins, such as hormone binding [76], chaperoning [69], or protein storage functions [38]. Based on 3D modelling, we predicted that EnSerp1's secondary and tertiary structures are also characteristic of serpins: they fold into an N-terminal mostly helical domain and a C-terminal $\beta$-barrel-like domain consisting of nine $\alpha$-helices and three $\beta$-sheets in total. Another crucial structure clearly recognisable in the model is the RCL connected to a $\beta$-sheet $\mathrm{A}$. This is important for proper inhibitory function, because the RCL is incorporated into the $\beta$-sheet $\mathrm{A}$ during conformational changes, after cleavage of the scissile bond (Fig. 1C) $[21,29,59]$. These properties are present in the earlier described serpin-like structures, such as antitrypsin (PDB: 7API) [18], ovalbumin (PDB: 1OVA) [90], antichymotrypsin (PDB: 2ACH) [6], and plasminogen activator 1(PAI1) (PDB: $1 \mathrm{C} 5 \mathrm{G})$ [66], as well as in the more recently described ones, such as serpin18 (PDB: 4R9I) [23], SRPN18 (PDB: 5C98) [63], and vaspin (PDB: 4IF8) [26].

Phylogenetic analyses have shown that EnSerp1 is related to other platyhelminth serpins. In early pre-analyses (including investigations of mammalian, fish, insect, and reptilian sequences), we observed a clustering of platyhelminth serpins into one clade (data not shown). Within this clade, serpins seemed to form two main serpin groups, A and B (see Fig. 2). The crucial distinction between these two groups is determined by the most significant insertion/deletion between amino acid residues 100-112 (for the alignment of all serpins, see Supplementary file 1). Sequences that form Group B have an insertion in this region, which suggests a possible differentiation of their purpose during evolution, although unfortunately, we have not been able to find any studies dealing with the 
A

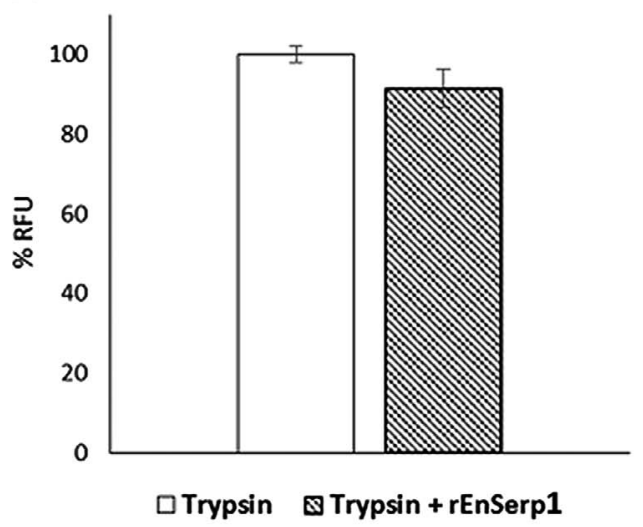

C

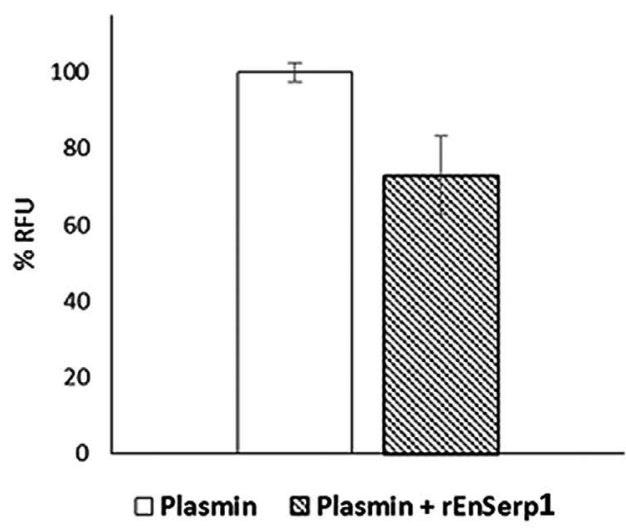

$\mathbf{E}$

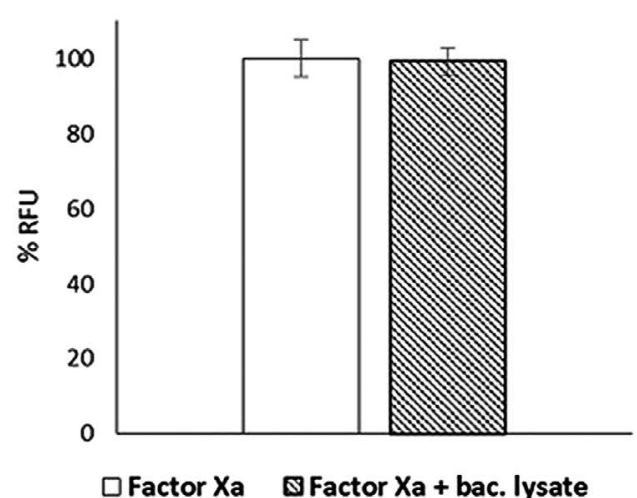

B

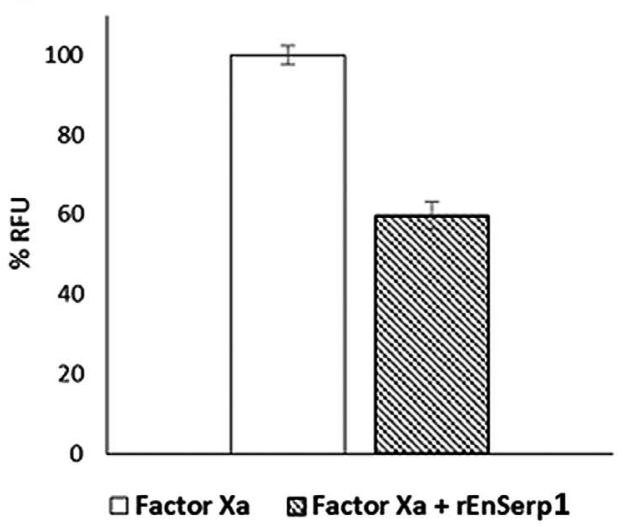

D

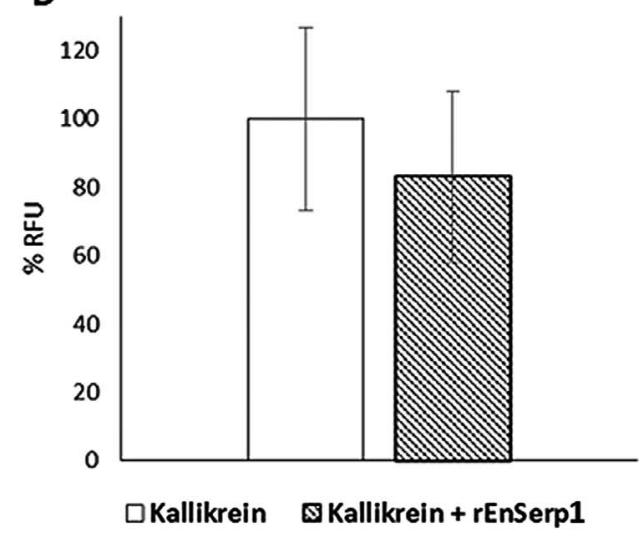

$\mathbf{F}$

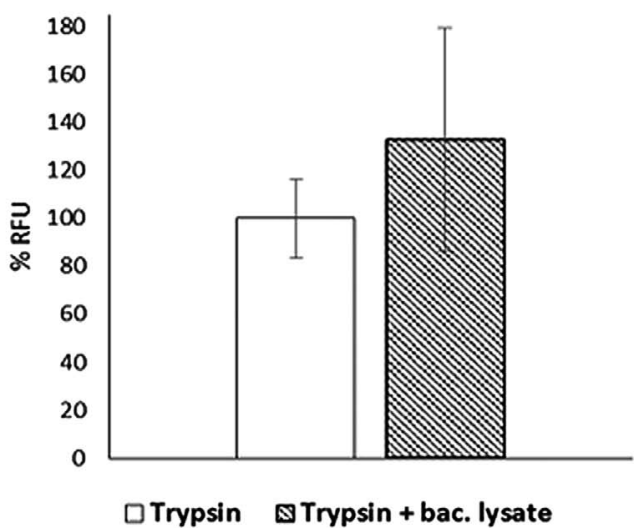

Figure 4. The inhibitory effect of rEnSerp1 on selected SPs. (A) trypsin; (B) factor Xa; (C) plasmin; (D) plasma kallikrein. Results of assays with a bacterial lysate instead of rEnSerp1: (E) factor Xa and F, trypsin. Data are expressed as a mean value \pm standard deviation.

specific functions associated with this region. According to the phylogenetic tree, EnSerp1 forms a separate branch in Group A (that lacks the abovementioned sequence region) and serpins belonging to this group are more closely related to trematode serpins than to their orthologs from the class Cestoda. This is an interesting observation, because monogeneans are generally believed to be evolutionarily closer to cestodes than to trematodes [58, 73]. According to our phylogenetic tree, another relevant sequence of the monogenean species G. salaris is not related to either of the two classes (i.e. neither Cestoda nor Trematoda) and forms a separate branch within Group A. This surprising outcome could be influenced by the fact that the $G$. salaris serpin sequence is not completely accurate since it was only predicted from the genome without any further reconfirmation.

Among all the serpins used for the phylogenetic analysis, only three had been characterised in more detail (GenBank: AAK57435.1 [98]; ADI60059.1 [99]; ABV57466.1 [35]), and only in one (GenBank: ABV57466.1) it had been shown that it has the ability to inhibit SPs [35]. This serpin was obtained from the lung trematode Paragonimus westermani and its sequence, like that of EnSerp1, belongs to Group A. 
Serpins typically form complexes at 1:1 molar ratio with target peptidase while using a unique irreversible mechanism of inhibition: they act as a suicide substrate [13]. This process is initiated by the formation of a covalent intermediate serpinpeptidase complex, which is then stabilised by a conformational translocation of the bound peptidase to the opposite pole of the serpin, where it distorts the peptidase active site $[55,88]$. This translocation of peptidase is related to the incorporation of the RCL into the abovementioned $\beta$-sheet A. In our kinetic measurements, we tested the inhibitory effect of rEnSerp 1 on several SPs, namely trypsin, factor Xa, plasmin, kallikrein, elastase, and thrombin. The last two were not inhibited at all. Incomplete inhibition of peptidases by rEnSerp1 in our experiments could be in part due to the origin of the peptidases we tested. Our measurements were conducted with commercial peptidases derived from porcine pancreas (trypsin and elastase), bovine plasma (factor Xa), and human plasma (thrombin, plasmin, and kallikrein), whereas the most probable targets of EnSerp1 are host peptidases from the common carp. Using a BLAST, we discovered only a $47 \%$ match between amino acid sequences of bovine factor Xa (GenBank: NP_001073682.1) and its predicted homolog from the carp genome (GenBank: KTF93720.1). Although the sequence similarity overall is relatively low, the crucial inhibitory potential is often related to the structure of the binding site within the reactive centre of a particular inhibitor molecule [25]. A similar situation was also observed for the other peptidases: human thrombin (GenBank: AAH51332.1) showed a 53\% match with carp (GenBank: KTF81317.1), human plasmin (GenBank: AAA36451.1) a 57\% match with carp (GenBank: KTF80813.1), porcine elastase (GenBank: 1207237A) a 62\% match with carp (GenBank: KTG34206.1), and porcine trypsin (GenBank: NP_001156363.1) a 65\% match with carp trypsin (GenBank: BAL04385.1). For plasma kallikrein, we could not find any homologous peptidase because in teleosts, the plasma kallikrein-kinin system cascade is absent [96].

Incomplete inhibition of selected SPs could also be associated with other factors. In addition to the relative specificity of rEnSerp1 discussed above, one can also assume that not all rEnSerp1 molecules in the examined sample were properly folded in an active conformation. It has been reported that due to an unstable native state, serpins are prone to polymerisation [49]. Polymerisation and incorrect folding can occur even at a physiological $\mathrm{pH}$ and temperature [75]. It is also possible that the inhibitory effect of serpins could be increased by including a cofactor into the reaction; for example, the inhibitory capacity of human antithrombin against thrombin was optimal when the reaction included the glycosaminoglycan heparin $[8,33,74,83]$. Taking this into consideration, we tried to inhibit factor Xa by rEnSerp1 in the presence of heparin (heparin sodium salt, $20 \mathrm{nM}$, Zentiva), but no inhibitory effect was observed (data not shown). In order to detect any possible residual contamination with inhibitory effect in the sample of purified rEnSerp1 expressed in bacteria, a control with bacterial lysate instead of rEnSerp1 was tested. In this case, enhanced hydrolytic activity towards the substrate was observed, which might reflect the presence of active bacterial peptidases in the sample that would cleave the GPR [68]. Nevertheless, the bacterial lysate sample alone did not show any inhibitory effect, which indicates that the inhibition achieved in our measurements was related solely to rEnSerp1.

Activated factor $\mathrm{X}$ is an important SP of the blood coagulation cascade: it converts prothrombin to thrombin, which then cleaves fibrinogen to fibrin that forms a blood clot. Among haematophagous parasites, inhibitors that affect this SP tend to play a significant role in feeding $[11,19,36,48,50]$. Plasmin participates in fibrinolysis by cleaving fibrin clots and is involved in host defence mechanisms by regulating immune cells such as monocytes, macrophages, and dendritic cells [91]. Plasma kallikrein, too, is involved in fibrinolysis: it generates plasmin from plasminogen. In mammals, its other important function is a conversion of kininogens to kinins, polypeptides which regulate inflammation and blood pressure [10]. As noted above, however, plasma kallikrein and high-molecular-weight kininogen are not present in the teleosts [96], which makes any speculations about a possible interaction between monogenean serpins and the kallikrein/kinin system of the host moot. Nevertheless, the observed influence of rEnSerp1 on factor Xa and plasmin has one other possible interpretation, namely that it plays a role in inhibiting the host complement cascade. It has been shown that both of these SPs can convert C3 and C5 components to their active forms (C3a, C5a) [1, 72], thereby propagating inflammation. Given that in fish, innate immunity is of great importance and inflammation is the first response [94], EnSerp1's interference with the peptidolytic activity of factor Xa and plasmin may be a way of preventing the host immune system from damaging the parasite's tissue.

\section{Conclusion}

In comparison to the other parasitic classes of platyhelminths, biochemical research tended to pay relatively little attention to Monogenea, although they include some species that have an economic impact, e.g. the Gyrodactylus salaris, the salmon fluke, which represents a significant problem for salmon farming. This situation seems to be slowly changing now with several recently published papers focused on proteins that function at the interface between the monogenean bloodfeeder E. nipponicum and its fish host [37, 40, 41]. The results of the present study contribute to a growing body of knowledge regarding these molecules and processes in which they participate. Our characterisation of the molecular/biochemical properties of a serpin from E. nipponicum (EnSerp1) is the first record of such a group of peptidase inhibitors in Monogenea. Based on the results of an in silico analysis, we can conclude that EnSerp1 has structural features that correspond to equivalent structures in other members of the serpin superfamily, especially those involved in the regulation of peptidases of the coagulation cascade and fibrinolysis (antithrombin III, heparin cofactor II and PAI-1). Total absence of experimental data unfortunately prevented us from making a relevant comparison with serpins from other monogenean taxa. The inhibitory effect of rEnSerp1 on the activity of factor Xa and plasmin, together with the presence of EnSerp1 in the excretory-secretory products of the worm, does, however, suggest that EnSerp1 works as an anti-inflammatory as well as an anticoagulant agent involved in parasite-host interactions. 


\section{Supplementary files}

Supplementary file 1: List of serpins used for phylogenetic analysis (PDF $269 \mathrm{~KB}$ ).

Supplementary file 2: Alignment of platyhelminth serpin sequences (TIFF $4750 \mathrm{~KB}$ ).

Supplementary materials are available at https://www. parasite-journal.org/10.1051/parasite/2018062/olm

\section{Ethics statement}

The maintenance and care of experimental animals was carried out in accordance with European Directive 2010/63/EU and Czech Acts 246/1992 Coll. and 359/2012 Coll. which regulate biomedical research involving animals. Experiments were performed with the legal consent of the Professional Ethics Committee of the Faculty of Science, Charles University, Prague, and the Branch for Research and Development of the Ministry of Education, Youth and Sports of the Czech Republic. The animal facility, its equipment, animal welfare, and accompanying services including maintenance of experimental animals, were approved by the Branch of Animal Commodities of the Ministry of Agriculture of the Czech Republic (approval no. 13060/2014-MZE-17214).

\section{Conflict of interest}

The authors declare that they have no competing interests.

Acknowledgements. The research was supported financially by the Czech Science Foundation (GBP505/12/G112, GAP506/12/1258) and Masaryk University (MUNI/A/1362/2016). Charles University institutional support (PROGRES Q43, UNCE 204017, and SVV 244-260432/2017) applied to LJ and MK. LM's work was supported by the project "Centre for Research of Pathogenicity and Virulence of Parasites" (No. CZ.02.1.01/0.0/0.0/16_019/0000759) funded by the European Regional Development Fund and the Ministry of Education, Youth and Sports of the Czech Republic. Work carried out in the Proteomics Core Facility was supported by a CIISB project (LM2015043) and project CEITEC 2020 (LQ1601), with financial support from the Ministry of Education, Youth and Sports of the Czech Republic. Computational resources were supplied by the Ministry of Education, Youth and Sports of the Czech Republic under the Projects CESNET (Project No. LM2015042) and CERITScientific Cloud (Project No. LM2015085) provided within the program Projects of Large Research, Development and Innovations Infrastructures. We would like to thank Professor John P. Dalton, Medical Biology Centre, School of Biological Sciences, Queen's University Belfast, for guidance during PR's research stay in his laboratory and for critical reading of the final version of the manuscript.

\section{Authors' contributions}

PR performed most of the experiments and wrote the manuscript. JV performed the transcriptome analysis. JI contributed to some molecular and immunochemical experiments (cloning, Western blotting). MB performed the phylogenetic analysis. AN helped with the purification of recombinant serpin, LJ helped with the fluorometric assays, while LM prepared the specific polyclonal antibodies and contributed to a discussion of the results in a biological context and to a critical reading and finalisation of the manuscript. DP and ZZ executed the mass spectrometry analysis; JD helped with the expression of recombinant serpin. MG and MK participated in planning the experiment design, provided advice during the research, and helped with the interpretation of results.

\section{References}

1. Amara U, Flierl MA, Rittirsch D, Klos A, Chen H, Acker B, Bruckner UB, Nilsson B, Gebhard F, Lambris JD, Huber-Lang M. 2010. Molecular intercommunication between the complement and coagulation cystems. Journal of Immunology, 185, $5628-5636$.

2. Aslam A, Quinn P, Mcintosh RS, Shi J, Ghumra A, Mckerrow JH, Bunting KA, Dunne DW, Doenhoff MJ, Morrison SL, Zhang K, Pleass RJ. 2008. Proteases from Schistosoma mansoni cercariae cleave $\operatorname{IgE}$ at solvent exposed interdomain regions. Molecular Immunology, 45, 567-574.

3. Bager R, Johansen JS, Jensen JK, Stensballe A, Jendroszek A, Buxbom L, Sørensen HP, Andreasen PA. 2013. Protein conformational change delayed by steric hindrance from an N-linked glycan. Journal of Molecular Biology, 425, 2867-2877.

4. Baglin TP, Carrell RW, Church FC, Esmon CT, Huntington JA. 2002. Crystal structures of native and thrombin-complexed heparin cofactor II reveal a multistep allosteric mechanism. Proceedings of the National Academy of Sciences of the United States of America, 99, 11079-11084.

5. Bandilla M, Valtonen ET, Suomalainen LR, Aphalo PJ, Hakalahti T. 2006. A link between ectoparasite infection and susceptibility to bacterial disease in rainbow trout. International Journal for Parasitology, 36, 987-991.

6. Baumann U, Huber R, Bode W, Grosse D, Lesjak M, Laurell CB. 1991. Crystal structure of cleaved human $\alpha 1$-antichymotrypsin at $2.7 \AA$ resolution and its comparison with other serpins. Journal of Molecular Biology, 218, 595-606.

7. Benson DA, Karsch-Mizrachi I, Lipman DJ, Ostell J, Wheeler DL. 2005. GenBank. Nucleic Acids Research, 33, 34-38.

8. Bhakuni T, Ali MF, Ahmad I, Bano S, Ansari S, Jairajpuri MA. 2016. Role of heparin and non heparin binding serpins in coagulation and angiogenesis: A complex interplay. Archives of Biochemistry and Biophysics, 604, 128-142.

9. Blanton RE, Licate LS, Aman RA. 1994. Characterization of a native and recombinant Schistosoma haematobium serine protease inhibitor gene product. Molecular and Biochemical Parasitology, 63, 1-11.

10. Bryant J, Shariat-Madar Z. 2009. Human plasma kallikreinkinin system: physiological and biochemical parameters. Cardiovascular \& Hematological Agents in Medicinal Chemistry, 7, 234-250.

11. Calvo E, Mizurini DM, Sá-Nunes A, Ribeiro JMC, Andersen JF, Mans BJ, Monteiro RQ, Kotsyfakis M, Francischetti IMB. 2011. Alboserpin, a factor $\mathrm{Xa}$ inhibitor from the mosquito vector of yellow fever, binds heparin and membrane phospholipids and exhibits antithrombotic activity. Journal of Biological Chemistry, 286, 27998-28010.

12. Carmona C, McGonigle S, Dowd AJ, Smith AM, Coughlan S, McGowran E, Dalton JP. 1994. A dipeptidylpeptidase secreted by Fasciola hepatica. Parasitology, 109(Pt 1), 113-118.

13. Carrell R, Travis J. 1985. $\alpha 1$-Antitrypsin and the serpins: variation and countervariation. Trends in Biochemical Sciences, 10, 20-24.

14. Carrell RW, Stein PE, Fermi G, Wardell MR. 1994. Biological implications of a $3 \AA$ structure of dimeric antithrombin. Structure, 2, 257-270. 
15. Chmelar J, Oliveira CJ, Rezacova P, Francischetti IMB, Kovarova Z, Pejler G, Kopacek P, Ribeiro JMC, Mares M, Kopecky J, Kotsyfakis M. 2011. A tick salivary protein targets cathepsin $\mathrm{G}$ and chymase and inhibits host inflammation and platelet aggregation. Blood, 117, 736-744.

16. Dalton JP, Clouhg KA, Jones MK, Brindley PJ. 1997. The cysteine proteinases of Schistosoma mansoni cercariae. Parasitology, 114, 105-112.

17. Dvorak J, Horn M. 2018. Serine proteases in schistosomes and other trematodes. International Journal for Parasitology, 48, 333-344.

18. Engh R, Löbermann H, Schneider M, Wiegand G, Huber R, Laurell C. 1989. The $\mathrm{S}$ variant of human $\alpha 1$-antitrypsin, structure and implications for function and metabolism. Protein Engineering, Design and Selection, 2, 407-415.

19. Gan W, Deng L, Yang C, He Q, Hu J, Yin H, Jin X, Lu C, Wu Y, Peng L. 2009. An anticoagulant peptide from the human hookworm, Ancylostoma duodenale that inhibits coagulation factors Xa and XIa. FEBS Letters, 583, 1976-1980.

20. van Gent D, Sharp P, Morgan K, Kalsheker N. 2003. Serpins: structure, function and molecular evolution. International Journal of Biochemistry \& Cell Biology, 35, 1536-1547.

21. Gettins PGW. 2002. Serpin structure, mechanism, and function. Chemical Reviews, 102, 4751-4803.

22. Ghendler Y, Arnon R, Fishelson Z. 1994. Schistosoma mansoni: Isolation and characterisation of Smpi56, a novel serine protease inhibitor. Experimental Parasitology, 78, 121-131.

23. Guo P-C, Dong Z, Zhao P, Zhang Y, He H, Tan X, Zhang W, Xia Q. 2015. Structural insights into the unique inhibitory mechanism of the silkworm protease inhibitor serpin 18 . Scientific Reports, 5, 11863.

24. Hammond GL, Smith CL, Goping IS, Underhill DA, Harley MJ, Reventos J, Musto NA, Gunsalus GL, Bardin CW. 1987. Primary structure of human corticosteroid binding globulin, deduced from hepatic and pulmonary cDNAs, exhibits homology with serine protease inhibitors. Proceedings of the National Academy of Sciences of the United States of America, 84, 5153-5157.

25. Hedstrom L. 2002. Serine protease mechanism and specificity. Chemical Reviews, 102, 4501-4523.

26. Heiker JT, Klöting N, Kovacs P, Kuettner EB, Sträter N, Schultz S, Kern M, Stumvoll M, Blüher M, Beck-Sickinger AG. 2013. Vaspin inhibits kallikrein 7 by serpin mechanism. Cellular and Molecular Life Sciences, 70, 2569-2583.

27. Hewitson JP, Grainger JR, Maizels RM. 2009. Helminth immunoregulation: The role of parasite secreted proteins in modulating host immunity. Molecular and Biochemical Parasitology, 167, 1-11.

28. Hirazawa N, Umeda N, Hatanaka A, Kuroda A. 2006. Characterization of serine proteases in the monogenean Neobenedenia girellae. Aquaculture, 255, 188-195.

29. Hopkins PCR, Carrell RW, Stone SR. 1993. Effects of mutations in the hinge region of serpins. Biochemistry, 32, $7650-7657$.

30. Howe KL, Bolt BJ, Cain S, Chan J, Chen WJ, Davis P, Done J, Down T, Gao S, Grove C, Harris TW, Kishore R, Lee R, Lomax J, Li Y, Muller HM, Nakamura C, Nuin P, Paulini M, Raciti D, Schindelman G, Stanley E, Tuli MA, Van Auken K, Wang D, Wang X, Williams G, Wright A, Yook K, Berriman M, Kersey P, Schedl T, Stein L, Sternberg PW. 2016. WormBase 2016: Expanding to enable helminth genomic research. Nucleic Acids Research, 44, D774-D780.

31. Howe KL, Bolt BJ, Shafie M, Kersey P, Berriman M. 2017. WormBase ParaSite - A comprehensive resource for helminth genomics. Molecular and Biochemical Parasitology, 215, 2-10.

32. Huber R, Carrell RW. 1989. Implications of the threedimensional structure of a1-Antitrypsin for structure and function of serpins. Biochemistry, 28, 8951-8966.

33. Huntington JA. 2003. Mechanisms of glycosaminoglycan activation of the serpins in hemostasis. Journal of Thrombosis and Haemostasis, 1, 1535-1549.

34. Huntington JA. 2011. Serpin structure, function and dysfunction. Journal of Thrombosis and Haemostasis, 9, 26-34.

35. Hwang JH, Lee WG, Na BK, Lee HW, Cho SH, Kim TS. 2009. Identification and characterization of a serine protease inhibitor of Paragonimus westermani. Parasitology Research, 104, 495-501.

36. Ibelli AMG, Kim TK, Hill CC, Lewis LA, Bakshi M, Miller S, Porter L, Mulenga A. 2014. A blood meal-induced Ixodes scapularis tick saliva serpin inhibits trypsin and thrombin, and interferes with platelet aggregation and blood clotting. International Journal for Parasitology, 44, 369-379.

37. Ilgová J, Jedličková L, Dvořáková $\mathrm{H}$, Benovics $\mathrm{M}$, Mikeš L, Janda L, Vorel J, Roudnický P, Potěšil D, Zdráhal Z, Gelnar M, Kašný M. 2017. A novel type I cystatin of parasite origin with atypical legumain-binding domain. Scientific Reports, 7, 17526.

38. Irving JA, Pike RN, Lesk AM, Whisstock JC. 2000. Phylogeny of the serpin superfamily: Implications of patterns of amino acid conservation for structure and function. Genome Research, $10,1845-1864$.

39. Ishida Y, Nagata K. 2011. Hsp47 as a collagen-specific molecular chaperone. Methods in Enzymology, 499, 167-182.

40. Jedličková L, Dvořáková H, Dvořák J, Kašný M, Ulrychová L, Vorel J, Žárský V, Mikeš L. 2018. Cysteine peptidases of Eudiplozoon nipponicum: a broad repertoire of structurally assorted cathepsins L in contrast to the scarcity of cathepsins B in an invasive species of haematophagous monogenean of common carp. Parasites \& Vectors, 11, 142.

41. Jedličková L, Dvořáková H, Kašný M, Ilgová J, Potěšil D, Zdráhal Z, Mikeš L. 2016. Major acid endopeptidases of the blood-feeding monogenean Eudiplozoon nipponicum (Heteronchoinea: Diplozoidae). Parasitology, 143, 494-506.

42. Johnson DJD, Langdown $\mathrm{J}$, Li W, Luis SA, Baglin TP, Huntington JA. 2006. Crystal structure of monomeric native antithrombin reveals a novel reactive center loop conformation. Journal of Biological Chemistry, 281, 35478-35486.

43. Kang J-M, Sohn W-M, Ju J-W, Kim T-S, Na B-K. 2010. Identification and characterization of a serine protease inhibitor of Clonorchis sinensis. Acta Tropica, 116, 134-140.

44. Kašný M, Mikeš L, Hampl V, Dvořák J, Caffrey CR, Dalton JP, Horák P. 2009. Peptidases of Trematodes. Advances in Parasitology, 69, 205-297.

45. Kawatsu H. 1978. Studies on the anemia of fish-IX. Nippon Suisan Gakkaishi, 44, 1315-1319.

46. Keane TM, Creevey CJ, Pentony MM, Naughton TJM, Mclnerney JO. 2006. Assessment of methods for amino acid matrix selection and their use on empirical data shows that ad hoc assumptions for choice of matrix are not justified. BMC Evolutionary Biology, 6, 29.

47. Kelly LA, Mezulis S, Yates C, Wass M, Sternberg M. 2015. The Phyre2 web portal for protein modelling, prediction, and analysis. Nature Protocols, 10, 845-858.

48. Kenneth KR, James AA, Stark KR, James AA. 1998. Isolation and characterization of the gene encoding a novel factor Xa-directed anticoagulant from the yellow fever mosquito, Aedes aegypti. Journal of Biological Chemistry, 273, 20802-20809.

49. Khan MS, Singh P, Azhar A, Naseem A, Rashid Q, Kabir MA, Jairajpuri MA. 2011. Serpin inhibition mechanism: A delicate 
balance between native metastable state and polymerization. Journal of Amino Acids, 2011, 1-10.

50. Kim TK, Tirloni L, Radulovic Z, Lewis L, Bakshi M, Hill C, da Silva Vaz I, Logullo C, Termignoni C, Mulenga A. 2015. Conserved Amblyomma americanum tick Serpin19, an inhibitor of blood clotting factors Xa and XIa, trypsin and plasmin, has anti-haemostatic functions. International Journal for Parasitology, 45, 613-627.

51. Komiyama T, Ray CA, Pickup DJ, Howard AD, Thornberry NA, Peterson EP, Salvesen G. 1994. Inhibition of interleukin-1 converting enzyme by the cowpox virus serpin CrmA: An example of cross-class inhibition. Journal of Biological Chemistry, 269, 19331-19337.

52. Kong Y, Chung YB, Cho SY, Choi SH, Kang SY. 1994. Characterization of three neutral proteases of Spirometra mansoni plerocercoid. Parasitology, 108(Pt 3), 359-368.

53. Konstanzová V, Koubková $B$, Kašný $M$, Ilgová J, Dzika E, Gelnar M. 2015. Ultrastructure of the digestive tract of Paradiplozoon homoion (Monogenea). Parasitology Research, 114, 1485-1494.

54. Konstanzová V, Koubková B, Kašný M, Ilgová J, Dzika E, Gelnar M. 2016. Excretory system of representatives from family Diplozoidae (Monogenea). Parasitology Research, 115, 1493-1500.

55. Lawrence DA, Ginsburg D, Day DE, Berkenpas MB, Verhamme IM, Kvassman JO, Shore JD. 1995. Serpin-protease complexes are trapped as stable acyl-enzyme intermediates. Journal of Biological Chemistry, 270, 25309-25312.

56. Le SQ, Gascuel O. 2008. An improved general amino acid replacement matrix. Molecular Biology and Evolution, 25, $1307-1320$.

57. Leboulle G, Rochez C, Louahed J, Rutti B, Brossard M, Bollen A, Godfroid E. 2002. Isolation of Ixodes ricinus salivary gland mRNA encoding factors induced during blood feeding. American Journal of Tropical Medicine and Hygiene, 66, 225-233.

58. Littlewood TD, Rohde K, Bray RA, Herniou E. 1999. Phylogeny of the Platyhelminthes and the evolution of parasitism. Biological Journal of the Linnean Society, 68, 257-287.

59. Loebermann H, Tokuoka R, Deisenhofer J, Huber R. 1984. Human $\alpha 1$-proteinase inhibitor. Journal of Molecular Biology, 177, 531-557.

60. Lopez Quezada LA, Sajid M, Lim KC, McKerrow JH. 2012. A blood fluke serine protease inhibitor regulates an endogenous larval elastase. Journal of Biological Chemistry, 287, 7074-7083.

61. Marshall CJ. 1993. Evolutionary relationships among the serpins. Philosophical Transactions of the Royal Society B: Biological Sciences, 342, 101-119.

62. Matejusová I, Koubková B, D’Amelio S, Cunningham CO. 2001. Genetic characterization of six species of diplozoids (Monogenea; Diplozoidae). Parasitology, 123, 465-474.

63. Meekins DA, Zhang X, Battaile KP, Lovell S, Michel K. 2016. $1.45 \AA$ resolution structure of SRPN18 from the malaria vector Anopheles gambiae. Acta Crystallographica Section F Structural Biology Communications, 72, 853-862.

64. Merckelbach A, Ruppel A. 2007. Biochemical properties of an intracellular serpin from Echinococcus multilocularis. Molecular and Biochemical Parasitology, 156, 84-88.

65. Molehin AJ, Gobert GN, McManus DP. 2012. Serine protease inhibitors of parasitic helminths. Parasitology, 139, 681-695.

66. Mottonen J, Strand A, Symersky J, Sweet RM, Danley DE, Geoghegan KF, Gerard RD, Goldsmith EJ. 1992. Structural basis of latency in plasminogen activator inhibitor-1. Nature, $355,270-273$.
67. Mourey L, Samama JP, Delarue M, Petitou M, Choay J, Moras D. 1993. Crystal structure of cleaved bovine antithrombin III at

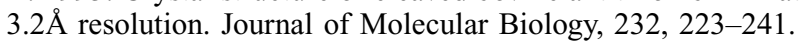

68. Nagy I, Banerjee T, Tamura T, Schoofs G, Gils A, Proost P, Tamura N, Baumeister W, De Mot R. 2003. Characterization of a novel intracellular endopeptidase of the alpha/beta hydrolase family from Streptomyces coelicolor A3(2). Journal of Bacteriology, 185, 496-503.

69. Nakai A, Satoh M, Hirayoshi K, Nagata K. 1992. Involvement of the stress protein HSP47 in procollagen processing in the endoplasmic reticulum. Journal of Cell Biology, 117, 903914.

70. Newport GR, McKerrow JH, Hedstrom R, Petitt M, McGarrigle L, Barr PJ, Agabian N. 1988. Cloning of the proteinase that facilitates infection by schistosome parasites. Journal of Biological Chemistry, 263, 13179-13184.

71. Nylund A, Hovland T, Hodneland K, Nilsen F, Lovik P. 1994. Mechanisms for transmission of infectious salmon anaemia (ISA). Diseases of Aquatic Organisms, 19, 95-100.

72. Oikonomopoulou K, Ricklin D, Ward PA, Lambris JD. 2012. Interactions between coagulation and complement - Their role in inflammation. Seminars in Immunopathology, 34, 151-165.

73. Olson PD, Littlewood DTJ, Bray RA, Mariaux J. 2001. Interrelationships and evolution of the tapeworms (Platyhelminthes: Cestoda). Molecular Phylogenetics and Evolution, 19, 443-467.

74. Olson ST, Bjork I. 1991. Predominant contribution of surface approximation to the mechanism of heparin acceleration of the antithrombin-thrombin reaction: Elucidation from salt concentration effects. Journal of Biological Chemistry, 266, 6353-6364.

75. Pearce MC, Powers GA, Feil SC, Hansen G, Parker MW, Bottomley SP. 2010. Identification and characterization of a misfolded monomeric merpin formed at physiological temperature. Journal of Molecular Biology, 403, 459-467.

76. Pemberton PA, Stein PE, Pepys MB, Potter JM, Carrell RW. 1988. Hormone binding globulins undergo serpin conformational change in inflammation. Nature, 336, 257-258.

77. Pettersen EF, Goddard TD, Huang CC, Couch GS, Greenblatt DM, Meng EC, Ferrin TE. 2004. UCSF Chimera - A visualization system for exploratory research and analysis. Journal of Computational Chemistry, 25, 1605-1612.

78. Pleass RJ, Kusel R, Woof JM. 2000. Cleavage of human IgE mediated by Schistosoma mansoni, 660111, 194-204.

79. Polzer M, Conradt U. 1994. Identification and partial characterization of the proteases from different developmental stages of Schistocephalus solidus (Cestoda: Pseudophyllidae. International Journal for Parasitology, 24, 967-973.

80. Prevot PP, Adam B, Boudjeltia KZ, Brossard M, Lins L, Cauchie P, Brasseur R, Vanhaeverbeek M, Vanhamme L, Godfroid E. 2006. Anti-hemostatic effects of a serpin from the saliva of the tick Ixodes ricinus. Journal of Biological Chemistry, 281, 26361-26369.

81. Prevot PP, Beschin A, Lins L, Beaufays J, Grosjean A, Bruys L, Adam B, Brossard M, Brasseur R, Zouaoui Boudjeltia K, Vanhamme L, Godfroid E. 2009. Exosites mediate the antiinflammatory effects of a multifunctional serpin from the saliva of the tick Ixodes ricinus. FEBS Journal, 276, 3235-3246.

82. Rao YZ, Yang TB. 2007. cDNA cloning, mRNA expression and recombinant expression of a cathepsin L-like cysteine protease from Neobenedenia melleni (Monogenea: Capsalidae). Aquaculture, 269, 41-53.

83. Rau JC, Beaulieu LM, Huntington JA, Church FC. 2007. Serpins in thrombosis, hemostasis and fibrinolysis. Journal of Thrombosis and Haemostasis, 5, 102-115. 
84. Rawlings ND, Barrett AJ, Finn R. 2016. Twenty years of the MEROPS database of proteolytic enzymes, their substrates and inhibitors. Nucleic Acids Research, 44, D343-D350.

85. Ronquist F, Teslenko M, Van Der Mark P, Ayres DL, Darling A, Höhna S, Larget B, Liu L, Suchard MA, Huelsenbeck JP. 2012. Mrbayes 3.2: Efficient bayesian phylogenetic inference and model choice across a large model space. Systematic Biology, $61,539-542$.

86. Šali A, Blundell TL. 1993. Comparative protein modelling by satisfaction of spatial restraints. Journal of Molecular Biology, 234, 779-815.

87. Schick C, Pemberton PA, Shi G, Kamachi Y, Bartuski J, Gornstein ER, Brmme D, Chapman HA, Silverman GA, Çataltepe S. 1998. Cross-class inhibition of the cysteine proteinases cathepsins $\mathrm{K}, \mathrm{L}$, and $\mathrm{S}$ by the serpin squamous cell carcinoma antigen 1: A kinetic analysis. Biochemistry, 37(15), 5258-5266.

88. Silverman GA, Lomas DA. 2004. Serpin identification, production, and characterization. Methods, 32, 71-72.

89. Stamatakis A. 2014. RAxML version 8: a tool for phylogenetic analysis and post-analysis of large phylogenies. Bioinformatics, 30, 1312-1313.

90. Stein PE, Leslie AGW, Finch JT, Carrell RW. 1991. Crystal structure of uncleaved ovalbumin at $195 \AA$ resolution. Journal of Molecular Biology, 221, 941-959.

91. Syrovets T, Lunov O, Simmet T. 2012. Plasmin as a proinflammatory cell activator., 92, 509-519.

92. Thompson JD, Higgins DG, Gibson TJ. 1994. CLUSTAL W: Improving the sensitivity of progressive multiple sequence alignment through sequence weighting, position-specific gap penalties and weight matrix choice. Nucleic Acids Research, $22,4673-4680$.
93. Valigurová A, Hodová I, Sonnek R, Koubková B, Gelnar M. 2011. Eudiplozoon nipponicum in focus: Monogenean exhibiting a highly specialized adaptation for ectoparasitic lifestyle. Parasitology Research, 108, 383-394.

94. Whyte SK. 2007. The innate immune response of finfish - A review of current knowledge. Fish and Shellfish Immunology, $23,1127-1151$.

95. Widmer C, Gebauer JM, Brunstein E, Rosenbaum S, Zaucke F, Drögemüller C, Leeb T, Baumann U. 2012. Molecular basis for the action of the collagen-specific chaperone Hsp47/ SERPINH1 and its structure-specific client recognition. Proceedings of the National Academy of Sciences of the United States of America, 109, 13243-13247.

96. Wong MKS, Takei Y. 2013. Lack of plasma kallikrein-kinin system cascade in teleosts. PLoS One, 8, 1-13.

97. Xu DH, Shoemaker CA, Klesius PH. 2007. Evaluation of the link between gyrodactylosis and streptococcosis of Nile tilapia, Oreochromis niloticus (L.). Journal of Fish Diseases, 30, 233-238.

98. Yan Y, Liu S, Song G, Xu Y, Dissous C. 2005. Characterization of a novel vaccine candidate and serine proteinase inhibitor from Schistosoma japonicum ( $\mathrm{Sj}$ serpin). Veterinary Parasitology, 131, 53-60.

99. Yang $\mathrm{Y}, \mathrm{Hu} \mathrm{D}$, Wang $\mathrm{L}$, Liang $\mathrm{C}, \mathrm{Hu} \mathrm{X}$, Wang $\mathrm{X}$, Chen J, $\mathrm{Xu}$ J, Yu X. 2009. Molecular cloning and characterization of a novel serpin gene of Clonorchis sinensis, highly expressed in the stage of metacercaria. Parasitology Research, 106, 221-225.

100. Zurawski TH, Mair GR, Maule AG, Gelnar M, Halton DW. 2003. Microscopical evaluation of neural connectivity between paired stages of Eudiplozoon nipponicum (Monogenea: Diplozoidae). Journal of Parasitology, 89, 198-200.

Cite this article as: Roudnický P, Vorel J, Ilgová J, Benovics M, Norek A, Jedličková L, Mikeš L, Potěšil D, Zdráhal Z, Dvořák J, Gelnar M \& Kašný M. 2018. Identification and partial characterization of a novel serpin from Eudiplozoon nipponicum (Monogenea, Polyopisthocotylea). Parasite 25, 61.

\section{PARASTE}

An international open-access, peer-reviewed, online journal publishing high quality papers on all aspects of human and animal parasitology

Reviews, articles and short notes may be submitted. Fields include, but are not limited to: general, medical and veterinary parasitology; morphology, including ultrastructure; parasite systematics, including entomology, acarology, helminthology and protistology, and molecular analyses; molecular biology and biochemistry; immunology of parasitic diseases; host-parasite relationships; ecology and life history of parasites; epidemiology; therapeutics; new diagnostic tools.

All papers in Parasite are published in English. Manuscripts should have a broad interest and must not have been published or submitted elsewhere. No limit is imposed on the length of manuscripts.

Parasite (open-access) continues Parasite (print and online editions, 1994-2012) and Annales de Parasitologie Humaine et Comparée (1923-1993) and is the official journal of the Société Française de Parasitologie. 